http://jmscr.igmpublication.org/home/ ISSN (e)-2347-176x ISSN (p) 2455-0450

crossref DOI: https://dx.doi.org/10.18535/jmscr/v8i1.163

Journal Of Medical Science And Clinical Research

\title{
A Study of Course and Outcome of Babies Weighing less than 1500 Grams at Birth after Discharge from NICU
}

\author{
Authors \\ Dr Naresh Gadi ${ }^{1}$, Dr S.D. Agrawal ${ }^{2}$, Dr Asit Mohan Mohapatra ${ }^{3}$, \\ Dr Satish Kumar Sethi ${ }^{4}$ \\ Department of Paediatrics, Hitech Medical College and Hospital, Bhubaneswar \\ *Corresponding Author \\ Dr Sasmita Devi Agrawal \\ Professor Dept. of Pediatrics, Hitech Medical College and Hospital, Bhubaneswar, India
}

\begin{abstract}
Introduction: WHO defines very low birth weight babies as birth weight $<1500$ gms at birth irrespective of gestational age. In India VLBW babies constitute $4-7 \%$ of live births and 30\% of neonatal death. They are prone to a large variety of complications such as hypothermia, RDS, infection and require proper NICU care. Based on the socioeconomic status of the parents, overcrowding of beds etc various institutions follow various guidelines to discharge VLBW babies. Hence this study aims to study the course and outcome of $V L B W$ babies discharged at 1500 gms weight.

Materials and Methods: This is a longitudinal follow up study done between September 2017-september 2018 with thorough history and examination for all the outborn and inborn vlbw babies based on a predesigned proforma. The criteria upon which the baby is discharged and the outcome were noted.

Results: Out of 472 babies admitted to NICU during the study 33(7\%) were VLBW. And $12 \%$ of them were discharged at $1500 \mathrm{gms}$ or less. 10 (83.3\%) came back for follow up and 2 (16.7\%) infants died. Both infants discharged at $<1200 \mathrm{gms}$ accounted for 100\% of deaths with main cause presumed to be sepsis. 6 out of 10 surviving babies achieved $15 \mathrm{~g} / \mathrm{kg} /$ day weight gain and 3 babies developed respiratory infections and 1 had seizures.

Conclusion: Discharge of a VLBW baby at 1500gms weight was found to be safe with proper parental counselling, appropriate newborn care and regular follow-up.
\end{abstract}

\section{Introduction}

"Children's health- Tomorrow's wealth"

Children are the wealth of any country. They are the most valuable asset for any society. They are the builders of the future of any nation.

The WHO defines Very low birth weight babies (VLBW) as birth weight $<1500$ grams at birth irrespective of gestational age. ${ }^{(1)}$ In India VLBW babies constitute $4 \%$ to $7 \%$ of the live births and approximately $30 \%$ of neonatal death. ${ }^{(2)}$
Risk factors for LBW include mothers with multiple pregnancies, previous low birth weight infants, poor nutrition, heart disease or hypertension, drug addiction, alcohol abuse insufficient prenatal care, environmental factors, smoking, lead exposure, other types of air pollutions, infection during pregnancy, poor blood flow to the uterus, Smoking, drinking, using drugs, and poor nutritional habits. ${ }^{2,3}$ 
Main complications found in low birth weight babies are Asphyxia, Hypothermia, Bronchopulmonary dysplasia, Hypoglycemia, Hyperbilirubinemia, infection, anemia, retinopathy and dehydration ${ }^{4}$.

ELBW infants are at more risk for the same health and neuro-developmental problems tahn VLBW babies. Neurological, neuro-developmental, neurosensory, and functional morbidities increase with decreasing birth weight. Ranges of surviving ELBW infants with moderate or severe disability start at 20-30 \% for the heavier ELBW group (700-1000 grams BW) and are reported to be approximately $30 \%$ to $50 \%$ for infants born at the limits of viability (less than 25 weeks of gestation). Many children demonstrate more than one disability - e.g. severe vision impairment, hearing impairment, cerebral palsy, mental retardation

The outcome in VLBW babies is mainly related to gestational age, birth weight, and diseases of the newborns, available care in facilities such as NICU, time of discharge, postnatal care and follow-up. ${ }^{(3)}$ However early home discharge of preterm infants is a priority in developing countries due to poor socio-economic status and personal reasons and overcrowding at neonatal care facilities etc. There is a wide variation in home discharge policies for VLBW infants which is constantly debated up on like $1800 \mathrm{gms}^{(4)}$ to 1500 gms $^{(5)}$ or no weight criteria at all ${ }^{(6)}$ weight at discharge play an important role in determining the survival and future outcome of these babies.

The study of the risk factors of neonatal death, indicators of the several aspects of mother and child healthcare, enables us to understand the links in the chain of determinant events that lead to death and to identify groups exposed to different risks. In the case of VLBW newborns, the study of factors associated with death may lead to the critical analysis of healthcare services and actions aimed at improving care for this group. Therefore, studies may help to identify the different healthcare needs and provide subsidies for interventions aimed at reducing infant death during the early prenatal period. Hence this study. Parents, physicians and schools are seeing increased numbers of children presenting with the major and minor neuro-developmental morbidities associated with prematurity. Some of these children have cerebral palsy, vision impairment, hearing loss, and/or mental retardation. Approximately one-third of ELBW children have been reported to receive educational placements outside of the regular classroom. ${ }^{9,10}$ VLBW children, which includes the ELBW population, show lower rates of high school graduation than normal BW children and are less likely to go to college than are full-term babies. ${ }^{11,12}$

The "take-home" message for the post-NICU management of the ELBW infant is that, given the high risk for the adverse sequelae of prematurity, every ELBW infant needs extra-vigilant monitoring and early referral for concerns. Many procedures that might be considered optional for larger LBW infants become essentially mandatory for the ELBW infant - including hearing assessment, close ophthalmologic follow-up, ongoing Neuro-developmental assessment, and assessment of school performance.

\section{Materials and Methodology \\ Objectives of the Study}

This was a longitudinal follow up study and was carried out in the Department of Pediatrics (NICU, Nursery), Department of Pediatrics (Out Patient Department), HI-TECH Medical College \& Hospital, Bhubaneswar in the time frame of November 2017 to October 2020 in-order to determine whether discharge at 1500 gms was a safe criteria .

The data for Mother's risk factors like hypertension, eclampsia, ante-partum hemorrhage, PROM, history of preterm, multiple gestations, polyhydramnios, oligohydramnios, antenatal steroids was also taken. The data of the baby from the Resuscitation necessities, APGAR Scoring, Gestational Age, Ballard scoring, need for nasal continuous positive airways pressure 
(NCPAP), surfactant therapy and mechanical ventilation ,Other problems encountered during neonatal stay, discharge criteria and the weight at discharge including other anthropometric measurements was taken.

Upon follow up the frequency of disease, complications, growth and developmental outcomes was assessed.

\section{Inclusion Criteria}

- Mothers of low birth weight babies who are interested to participate in the study.

- All very low birth weight babies admitted to NICU at HI-TECH Medical College \& Hospital, Bhubaneswar and all the VLBW babies attending the outpatients Department for follow up by reviewing their hospital records if available.

\section{Exclusion Criteria}

- Mothers with physical disabilities and impairments, mothers who are not interested to participate in the study.

- Very low birth weight babies who cannot be followed up because of various reasons including refusal of consent.

Very low birth weight babies having multiple congenital anomalies incompatible with life or suffering major trauma during perinatal or postnatal period were not included

Before enlisting for this study, written informed consent was obtained from the parents and statistical data was analysed using SPSS software.

\section{Results and Discussion}

Total of 530 neonates were admitted over two years hospitalized in HI-TECH Medical College \& Hospital, Bhubaneswar NICU, out of which 110 were VLBW neonates. 42 patients were excluded as 60 of which hospitalized after 24 hours and 8 others were discharged against medical advice by parent's request. In these 60 babies with birth weight less than $1500 \mathrm{~g}$ admitted in NICU and gestational age ranging from 23 to 37 weeks were studied.
As seen in table No. 1, it was observed that $56.67 \%$ mothers were in $21-25$ years age group, $31.67 \%$ in 26 - 30 years age group and $11.67 \%$ of mothers were in $31-35$ years age group. The mean age of mother was $26.45 \pm 2.31$. The incidence of very low birth weight was $93.33 \%$ in primi and $6.67 \%$ in multipara. $98.33 \%$ babies were delivered by LSCS and $1.67 \%$ were delivered by spontaneous vaginal delivery. $65.00 \%$ mothers were residents of urban area and $35.00 \%$ patients were from rural area. $68.33 \%$ patients had consanguinity in marriage whereas $31.67 \%$ were non consanguinous. $78.33 \%$ patients were literate and $21.67 \%$ patient was found illiterate. $73.33 \%$ patients had occupation as House wife and $26.67 \%$ patients were working women.

$51.67 \%$ of babies had gestational age between 23 to 27 weeks, $26.67 \%$ babies between 28 to 32 weeks, $18.33 \%$ babies between 33 to 37 weeks and $3.33 \%$ had gestational age more than 37 weeks. (Table 1).

Table No. 1 Characteristics of Mothers of very low birth weight infants admitted to NICU

\begin{tabular}{|c|c|c|c|}
\hline \multicolumn{2}{|c|}{ Social Profile of Mothers } & \multirow{2}{*}{$\begin{array}{c}\begin{array}{c}\text { No. of } \\
\text { Patients }\end{array} \\
34\end{array}$} & \multirow{2}{*}{$\begin{array}{c}\begin{array}{c}\text { Percentage } \\
(\%)\end{array} \\
56.67 \% \\
\end{array}$} \\
\hline Mothers Age & $21-25$ & & \\
\hline in Years & $26-30$ & 19 & $31.67 \%$ \\
\hline & $31-35$ & 7 & $11.67 \%$ \\
\hline \multirow[t]{2}{*}{ Parity } & Primi & 56 & $93.33 \%$ \\
\hline & Multi & 4 & $6.67 \%$ \\
\hline \multirow{2}{*}{$\begin{array}{l}\text { Mode of } \\
\text { Delivery }\end{array}$} & LSCS & 59 & $98.33 \%$ \\
\hline & $\begin{array}{l}\text { Vaginal } \\
\text { Delivery }\end{array}$ & 1 & $1.67 \%$ \\
\hline \multirow{2}{*}{$\begin{array}{l}\text { Residential } \\
\text { Area }\end{array}$} & Urban & 39 & $65.00 \%$ \\
\hline & Rural & 21 & $35.00 \%$ \\
\hline \multirow{4}{*}{$\begin{array}{l}\text { Gestational } \\
\text { Age }\end{array}$} & $23-27$ & 31 & $51.67 \%$ \\
\hline & $28-32$ & 16 & $26.67 \%$ \\
\hline & $33-37$ & 11 & $18.33 \%$ \\
\hline & $>37$ & 2 & $3.33 \%$ \\
\hline \multirow[t]{2}{*}{ Consanguinity } & Yes & 41 & $68.33 \%$ \\
\hline & No & 19 & $31.67 \%$ \\
\hline \multirow[t]{2}{*}{ Education } & Literate & 47 & $78.33 \%$ \\
\hline & Illiterate & 13 & $21.67 \%$ \\
\hline \multirow[t]{2}{*}{ Occupation } & House Wife & 44 & $73.33 \%$ \\
\hline & Working & 16 & $26.67 \%$ \\
\hline
\end{tabular}


Table No. 2 Conditions of Mothers of very low birth weight infants admitted to NICU

\begin{tabular}{|l|c|c|c|}
\hline \multicolumn{2}{|l|}{ Risk Factors } & No. of Patients & $\begin{array}{c}\text { Percentage } \\
(\%)\end{array}$ \\
\hline \multirow{2}{*}{ Anemia } & Yes & 46 & $76.67 \%$ \\
\cline { 2 - 4 } & No & 14 & $23.33 \%$ \\
\hline \multirow{2}{*}{ Hypertension } & Yes & 13 & $21.67 \%$ \\
\cline { 2 - 4 } & No & 47 & $78.33 \%$ \\
\hline \multirow{2}{*}{ Diabetes Mellitus } & Yes & 2 & $3.33 \%$ \\
\cline { 2 - 4 } & No & 58 & $96.67 \%$ \\
\hline \multirow{3}{*}{ RH Negative } & Yes & 19 & $31.67 \%$ \\
\cline { 2 - 4 } & No & 41 & $68.33 \%$ \\
\hline \multirow{3}{*}{ HIV } & Yes & 11 & $18.33 \%$ \\
\cline { 2 - 4 } & No & 49 & $81.67 \%$ \\
\hline \multirow{2}{*}{ Hepatitis - B } & Yes & 0 & $0.00 \%$ \\
\cline { 2 - 4 } & No & 60 & $100.00 \%$ \\
\hline \multirow{2}{*}{ Syphilis } & Yes & 0 & $0.00 \%$ \\
\cline { 2 - 4 } & No & 60 & $100.00 \%$ \\
\hline Other Medical Problems & Yes & 0 & $0.00 \%$ \\
\cline { 2 - 4 } & No & 60 & $100.00 \%$ \\
\cline { 2 - 4 } & Yes & 22 & $36.67 \%$ \\
\hline Hypothyroid & No & 38 & $63.33 \%$ \\
\cline { 2 - 4 } & No & 42 & $30.00 \%$ \\
\hline \multirow{2}{*}{ Hes } & 18 & \\
\hline
\end{tabular}

Table No. 3 Characteristics of very low birth weight infants admitted to NICU

\begin{tabular}{|c|c|c|c|}
\hline \multicolumn{2}{|c|}{$\begin{array}{l}\text { Characteristics of very low birth weight } \\
\text { infants }\end{array}$} & $\begin{array}{l}\text { No. of } \\
\text { Patients }\end{array}$ & $\begin{array}{c}\text { Percentage } \\
(\%)\end{array}$ \\
\hline \multirow[t]{3}{*}{ Birth Weight } & $<1000$ gms & 29 & $48.33 \%$ \\
\hline & $1000-1200$ gms & 13 & $21.67 \%$ \\
\hline & $1200-1500 \mathrm{gms}$ & 18 & $30.00 \%$ \\
\hline \multirow[t]{2}{*}{ Gender of Babies } & Male & 38 & $63.33 \%$ \\
\hline & Female & 22 & $36.67 \%$ \\
\hline \multirow{2}{*}{$\begin{array}{l}\text { Resuscitation } \\
\text { Required }\end{array}$} & Yes & 53 & $88.33 \%$ \\
\hline & $\mathrm{No}$ & 7 & $11.67 \%$ \\
\hline \multirow[t]{2}{*}{ Delivery } & Term & 2 & $3.33 \%$ \\
\hline & Preterm & 58 & $96.67 \%$ \\
\hline \multirow{2}{*}{$\begin{array}{l}\text { Cried Immediately } \\
\text { After Birth }\end{array}$} & Yes & 53 & $88.33 \%$ \\
\hline & No & 7 & $11.67 \%$ \\
\hline \multirow{3}{*}{$\begin{array}{l}\text { Apgar Score at } 1 \\
\text { minute }\end{array}$} & 0 to 4 & 25 & $41.67 \%$ \\
\hline & 5 to 7 & 20 & $33.33 \%$ \\
\hline & 8 to 10 & 15 & $25.00 \%$ \\
\hline \multirow{3}{*}{$\begin{array}{l}\text { Apgar Score at } 5 \\
\text { minute }\end{array}$} & 0 to 4 & 7 & $11.67 \%$ \\
\hline & 5 to 7 & 13 & $21.67 \%$ \\
\hline & 8 to 10 & 40 & $66.67 \%$ \\
\hline \multirow[t]{2}{*}{ Outcome } & Death & 7 & $11.67 \%$ \\
\hline & Survival & 53 & $88.33 \%$ \\
\hline
\end{tabular}


Figure No. 1 Graph showing Characteristics of very low birth weight infants admitted to NICU

\section{Characteristics of very low birth weight infants}

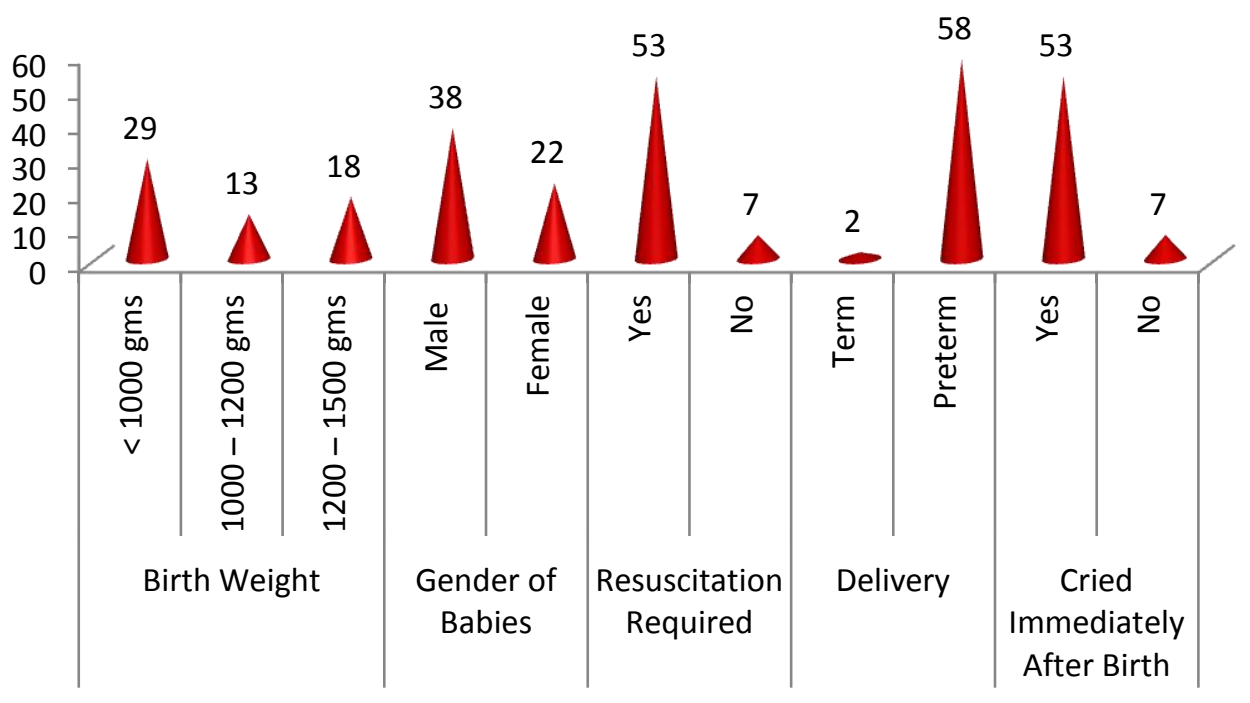

As illustrated in Table No. 3, 48.33\% infants were VLBW, $21.67 \%$ infants ELBW and $30 \%$ between 1200 to 1500 gms. $63.33 \%$ infants were male and $36.67 \%$ were female. In this study $88.33 \%$ infants had required resuscitation and $11.67 \%$ infants did not. $3.33 \%$ infants were delivered in term and $96.67 \%$ infants were delivered preterm.

$88.33 \%$ very low birth weight infants were cried immediately after birth whereas $11.67 \%$ infants did not cry immediately. It was seen that $41.67 \%$ infants had 0 to 4 apgar score at 1 minute, $33.33 \%$ infants were 5 to 7 apgar score at 1 minute and $25.00 \%$ infants were 8 to 10 apgar score at 1 minute. In this study $11.67 \%$ infants were 0 to 4 apgar score at 5 minute, $21.67 \%$ infants were 5 to 7 apgar score at 5 minute and $66.67 \%$ infants were 8 to 10 apgar score at 5 minute. The outcome as death of very low birth weight infants were $11.67 \%$ and $88.33 \%$ infants were survive after discharge from NICU.

Table No. 4 : Association of Gender of Infants with the outcome of infants

\begin{tabular}{|l|c|c|c|c|}
\hline \multirow{2}{*}{ Gender of Infants } & \multicolumn{2}{|c|}{ Outcome } & \multirow{2}{*}{ Total } & \multirow{2}{*}{ P Value } \\
\cline { 2 - 3 } & $\begin{array}{c}\text { Death } \\
(\%)\end{array}$ & $\begin{array}{c}\text { Survived } \\
(\%)\end{array}$ & & \\
\hline \multirow{2}{*}{ Male } & 2 & 36 & 38 & \\
\hline \multirow{2}{*}{ Female } & $(5.3 \%)$ & $(94.7 \%)$ & $(100.0 \%)$ & \multirow{2}{*}{ Chi Square $=2.603$} \\
\cline { 1 - 3 } Total & 5 & 17 & 22 & $\mathrm{P}=0.107$ \\
& $(22.7 \%)$ & $(77.3 \%)$ & $(100.0 \%)$ & \\
\hline
\end{tabular}

From the above table it was seen that survival of very low birth weight infants did not correlate with gender of infants. A chi-square value is 2.603 with $\mathrm{P}$ value 0.107 which indicates that outcome was not found statistically significant with gender of infants at $95 \%$ confidence interval. 
Table No. 5: Association of Gestational Age with the outcome of infants

\begin{tabular}{|c|c|c|c|c|}
\hline \multirow[b]{2}{*}{ Gestational Age } & \multicolumn{2}{|c|}{ Outcome } & \multirow[b]{2}{*}{ Total } & \multirow[b]{2}{*}{ P Value } \\
\hline & $\begin{array}{c}\text { Death } \\
(\%)\end{array}$ & $\begin{array}{c}\text { Survived } \\
(\%)\end{array}$ & & \\
\hline $23-27$ & $\begin{array}{c}4 \\
(12.9 \%)\end{array}$ & $\begin{array}{c}27 \\
(87.1)\end{array}$ & $\begin{array}{c}31 \\
(100.0 \%)\end{array}$ & \multirow{5}{*}{$\begin{array}{c}\text { Chi Square }=0.392 \\
P=1.00\end{array}$} \\
\hline $28-32$ & $\begin{array}{c}2 \\
(12.5 \%) \\
\end{array}$ & $\begin{array}{c}14 \\
(87.5 \%) \\
\end{array}$ & $\begin{array}{c}16 \\
(100.0 \%) \\
\end{array}$ & \\
\hline $33-37$ & $\begin{array}{c}1 \\
(9.1 \%)\end{array}$ & $\begin{array}{c}10 \\
(90.9 \%)\end{array}$ & $\begin{array}{c}11 \\
(100.0 \%)\end{array}$ & \\
\hline$>\mathbf{3 7}$ & $\begin{array}{c}0 \\
(0.0 \%) \\
\end{array}$ & $\begin{array}{c}2 \\
(100.0 \%)\end{array}$ & $\begin{array}{c}2 \\
(100.0 \%)\end{array}$ & \\
\hline Total & $\begin{array}{c}7 \\
(11.7 \%)\end{array}$ & $\begin{array}{c}53 \\
(88.3 \%)\end{array}$ & $\begin{array}{c}60 \\
(100.0 \%)\end{array}$ & \\
\hline
\end{tabular}

It was observed that survival of very low birth weight infants did not correlate with gestational age of mothers. A chi-square value is 0.392 with $\mathrm{P}$ value 1.00 which indicates that outcome was not found statistically significant with gestational age of mothers at $95 \%$ confidence interval.

Table No. 6 Association of Birth Weight of infants with the outcome of infants

\begin{tabular}{|c|c|c|c|c|}
\hline \multirow[t]{2}{*}{ Birth Weight of Infants } & \multicolumn{2}{|c|}{ Outcome } & \multirow[t]{2}{*}{ Total } & \multirow[t]{2}{*}{ P Value } \\
\hline & $\begin{array}{c}\text { Death } \\
(\%)\end{array}$ & $\begin{array}{c}\text { Survived } \\
(\%)\end{array}$ & & \\
\hline$<1000$ gms & $\begin{array}{c}4 \\
(13.8 \%) \\
\end{array}$ & $\begin{array}{c}25 \\
(86.2 \%) \\
\end{array}$ & $\begin{array}{c}29 \\
(100.0 \%) \\
\end{array}$ & \multirow[t]{4}{*}{$\begin{array}{l}\text { Chi Square }=4.147 \\
\mathrm{P}=0.126\end{array}$} \\
\hline $1000-1200$ gms & $\begin{array}{c}3 \\
(23.1 \%)\end{array}$ & $\begin{array}{c}10 \\
(76.9 \%)\end{array}$ & $\begin{array}{c}13 \\
(100.0 \%)\end{array}$ & \\
\hline $1200-1500$ gms & $\begin{array}{c}0 \\
(0.0 \%)\end{array}$ & $\begin{array}{c}18 \\
(100.0 \%)\end{array}$ & $\begin{array}{c}18 \\
(100.0 \%)\end{array}$ & \\
\hline Total & $\begin{array}{c}7 \\
(11.7 \%)\end{array}$ & $\begin{array}{c}53 \\
(88.3 \%)\end{array}$ & $\begin{array}{c}60 \\
(100.0 \%)\end{array}$ & \\
\hline
\end{tabular}

It was found that survival of very low birth weight infants did not correlate with birth weight of infants. A chi-square value is 4.147 with $\mathrm{P}$ value
0.126 which indicates that outcome was not found statistically significant with birth weight of infants at $95 \%$ confidence interval (Table 12).

Figure No. 2 Graph showing Association of Birth Weight of infants with the outcome of infants

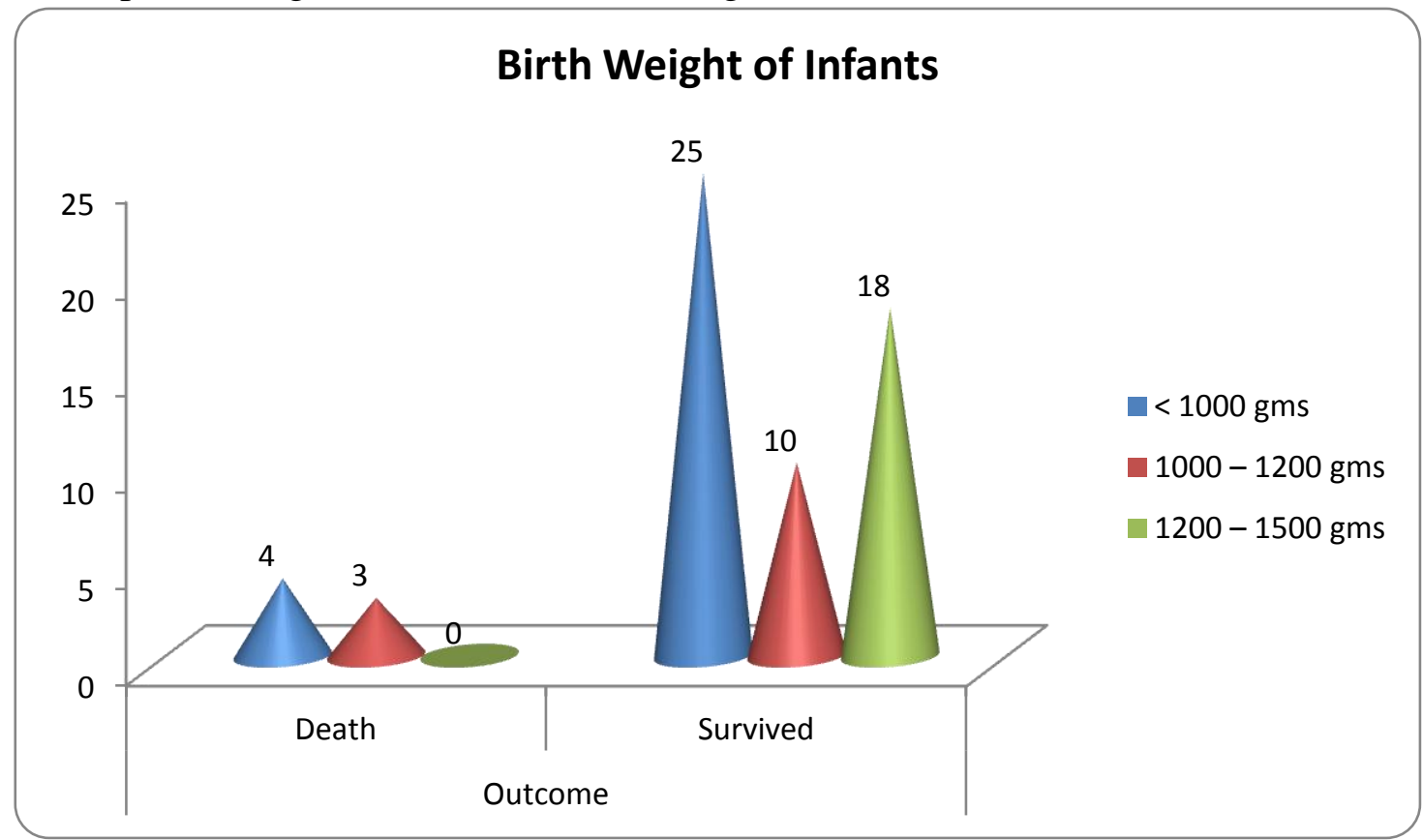


It was seen that survival of very low birth weight infants did not correlate with delivery. A chisquare value is 0.357 with $P$ value 0.550 which indicates that outcome was not found statistically significant with delivery at $95 \%$ confidence interval

It was found that survival of very low birth weight infants did not correlate with anemia of mothers. A chi-square value is 0.016 with $\mathrm{P}$ value 0.899 which indicates that outcome was not found statistically significant with anemia of mothers at 95\% confidence interval.

It was found that survival of very low birth weight infants did not correlate with multiple gestations of mothers. A chi-square value is 0.051 with $\mathrm{P}$ value 0.822 which indicates that outcome was not found statistically significant with multiple gestations of mothers.

It was found that survival of very low birth weight infants did notcorrelate with Socio-Economic Status of mothers. A chi-square value is 1.404 with $\mathrm{P}$ value 0.496 which indicates that outcome was not found statistically significant with SocioEconomic Status of mothers. Mean gestational age of low birth weight infants admitted in NICU is 34.45 with standard deviation 2.19 of survived infants whereas mean gestational age of mothers 29.78 with standard deviation 1.36 of death infants.

It is found that mean birth weight of survived infants admitted in NICU is 1223.35 with standard deviation 132.22 and means birth weight of death infants is 1087.03 with standard deviation 124.56 of death infants.

In this study it was found that survival of very low birth weight infants correlates with educational status of mothers. A chi-square value is 15.119 with $\mathrm{P}$ value 0.001 which indicates that outcome was found to be statistically significant with educational status of mothers at $95 \%$ confidence interval. In present studyit was observed that survival of very low birth weight infants correlates with residential area of mothers. A chi-square value is 6.613 with $P$ value 0.010 which indicates that outcome was found to be statistically significant with residential area of mothers at $5 \%$ level of significance

\section{Conclusion}

Birth weight and gestational age specifically predicts survival of preterm VLBW babies, facilitating decision making for obstetricians, neonatologists and parents. In the present study total survival rate was $88.3 \%$ with a mortality of $11.7 \%$.

Survival among infants weighing between 1000 1200 grams is poor. In addition to severe prematurity, the poor survival among these infants (1000 - 1200 grams) is most likely related to the fact that they were not offered mechanical ventilation. Mechanical ventilation should be offered to infants weighing between 1000 - 1200 grams as it may improve their survival even in institutions with limited resources.

Common antenatal and perinatal predictors of mortality in VLBW infants in India include maternal bleed, failure to administer antenatal steroids, low Apgar score, apnoea, extreme prematurity, neonatal septicaemia and shock.

Birth weight and gestational age specifically predicts survival of preterm VLBW babies, facilitating decision making for obstetricians, neonatologists and parents. Preterm VLBW infants have varying effects in terms of psychological and financial burden on family in developing countries like India. The factors leading to VLBW delivery in developing countries like India are modifiable and preventable.

This study concluded that significant difference found in course and outcomes of very low weight babies whose weight is less than 1500 grams after discharge from NICU attending OPD. This study also conclude that educational status of mothers, residential area of mothers and antenatal steroids are plays an important role in the outcome of very low weight babies whose weight is less than 1500 grams after discharge from NICU. This study also determines 1500 gms weight of babies at discharge may be a safe criteria for early 
discharge. To improve outcome for out born babies, high risk pregnancies should be delivered at tertiary care centres. Early use of full course of antenatal steroids and support for regionalized transport teams can further improve neonatal outcomes. A continuing audit of these measures should be encouraged, and the results should be made available to all health care workers working in obstetrics and neonatology. Individual family status like educational qualification, residential area of the family and awareness regarding the care of babies shall be improved by the mothers as well as family members and it shall be look forward by the primary health centres to improve outcome of low birth weight babies.

\section{Bibliography}

1. Manoj Yadav. Text book of child health nursing. 1 st ed. 2011.P 313.

2. Labor and delivery - Low birth weight. Umm, education 2008-10-22.Retrived 2011-01-05.

3. Lewtas J. Air pollution combustion emissions: characterization of causative agents and mechanisms associated with cancer, reproductive and cardiovascular effects. Mutat Res.2007 Nov-Dec; 636(13):95-133.

4. Stevens-Simon C, Orieans M. Low Birth weight Prevention programs; the enigma of failure.Birth.1999 sep;(3);184-91

5. URL:http://vihealthcare.com/topics/medic aldepartmenta/pediatrics/lowbirths weight/index.html.

6. Dutta D.C. text book obstetrics including perinatology and contraception. 7 th edition. new central book agency (P)ltd. London.2011; 457-8.

7. Low birth weight criteria for determining disability in infants and children summary. Journal US department of health and human service. National library of medicine bookshelf. AHRQ; 2003 March.
8. World Health Organization, International statistical classification of diseases and related health problems, tenth revision, World Health Organization, Geneva, 1992.

9. Tessa Wardlaw, Senior Programme Officer, Statistics and Monitoring, Division of Policy and Planning, UNICEF, New York; 2004.United Nations Children's Fund and World Health Organization, Low birth weight: Country, regional and global estimates

10. National Family Health Survey -3 (NFHS -3), 2005-06: India: Volume-1Mumbai: IIPS. P. 225-6.

11. Idris MZ, Gupta A, Mohan U, Srivastava AK, Das V. Maternal Health and Low Birth Weight Among Institutional Deliveries. Indian J Com Med 2000;25(4):156-60 .

12. Kumar SG, Harshakumar HN, Jayaram S, Kotian MS. Determinants of Low Birth Weight: A Case Control Study in a District Hospital in Karnataka. Indian J Pediatr 2010;77 (1):87-9. 